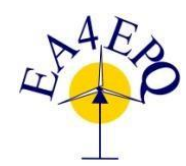

International Conference on Renewable Energies and Power Quality (ICREPQ'16) Madrid (Spain), $4^{\text {th }}$ to $6^{\text {th }}$ May, 2016

Renewable Energy and Power Quality Journal (RE\&PQJ)

ISSN 2172-038 X, No.14 May 2016

\title{
Production of synthesis gas from dry reforming of propane with carbon dioxide over ceria-promoted nickel foam catalysts
}

J. Karuppiah ${ }^{1}$, E. Linga Reddy ${ }^{2}$, M.S.P. Sudhakaran ${ }^{1}$ and S.B. Lee ${ }^{1}$

${ }^{1}$ Department of Chemical and Biological Engineering Jeju National University, Jeju 690-756 (Korea)

Phone/Fax number:+82-64-754-3683/+82-64-755-3670, e-mail: sblee@ jejunu.ac.kr

${ }^{2}$ Department of Chemical Engineering, Kyungpook National University, Daegu 702-701 (Korea) 


\begin{abstract}
A series of nickel foam supported cerai catalysts (ceria/NiF) for dry reforming of propane with carbon dioxide were prepared and their performance were evaluated at temperatures in the range of $520-600^{\circ} \mathrm{C}$. Among the catalysts examined the 4 wt. $\% \mathrm{CeO}_{2} / \mathrm{NiF}$ exhibited better low-temperature activity for the DRP, which is attributed to the formation of wellisolated nanosize $\mathrm{CeO}_{2}$ particles and highly reducible metal oxide species over the NiF support. The XPS and temperature programmed reduction (TPR) data also supported the incorporation of ceria into the $\mathrm{NiO}$ surface layer formed over $\mathrm{NiF}$ support, which was substantially higher in $4 \% \mathrm{CeO}_{2 /} \mathrm{NF}$ catalyst. Due to these favorable properties, the 4 wt. $\% \mathrm{CeO}_{2} / \mathrm{NiF}$ could be considered as an excellent catalyst for DRP.
\end{abstract}

\section{Key words}

Syngas, Propane reforming, Nickel foam, Ceria, Catalytic activity

\section{Introduction}

The generation of synthesis gas (syngas; a mixture of $\mathrm{H}_{2}$ and $\mathrm{CO}$ ) from hydrocarbons has received great attention owing to its wide range of applications towards sustainable and green energy technologies. Steam reforming and $\mathrm{CO}_{2}$ dry reforming are well-known syngas production processes. The dry reforming process has widely been used to convert natural gas into syngas. Recently, catalytic dry reforming of propane (DRP) into syngas with a low $\mathrm{H}_{2} / \mathrm{CO}$ ratio holds great promise in terms of effective utilization of $\mathrm{CO}_{2}$ and petroleum for various small-scale applications [1-2]. Mesoporous nickel foam $(\mathrm{NiF})$ with open-network structure has been considered as an excellent choice for catalysts or catalyst support for various applications $[3,4]$. $\mathrm{NiF}$ supports are ubiquitous because catalytic reactors made of $\mathrm{NiF}$ have many advantages over conventional packed-bed reactors, including high geometric surface area, low pressure drop even at high flow rates, efficient mass transfer, and high thermo-mechanical stability. In this work, mesoporous NiF supported ceria $\left(\mathrm{CeO}_{2} / \mathrm{NiF}\right)$ nanocatalysts with 2,3 and 4 wt.\% nominal $\mathrm{Ce}$ contents have been prepared by impregnation method, which were characterized by various techniques such as Xray diffraction (XRD), field emission scanning electron microscopy (SEM), X-ray photoelectron spectroscopy (XPS) and Raman spectroscopy.

\section{Experimental}

The NiF (thickness: $1.6 \mathrm{~mm}$ ) purchased from MTI Korea was first sonicated in 10 wt.\% $\mathrm{HCl}$ solution in order to remove surface oxide layer, and then washed with deionized water and ethanol twice. So as to incorporate $\mathrm{CeO}_{2}$ into the $\mathrm{NiF}$ at different concentrations (2-4 wt.\%), a simple impregnation method was used. In detail, a given amount of cerium nitrate $\left(\mathrm{Ce}\left(\mathrm{NO}_{3}\right)_{3} \cdot 6 \mathrm{H}_{2} \mathrm{O}\right)$ was dissolved in deionized water, and the pre-treated $\mathrm{NiF}\left(4 \times 4 \mathrm{~cm}^{2}\right)$ was immersed in the aqueous cerium nitrate solution. Finally, the $\mathrm{NiF}$ was taken out from the aqueous solution and dried overnight at room temperature before the calcination at $500^{\circ} \mathrm{C}$ for $5 \mathrm{~h}$ in air. The $\mathrm{CeO}_{2}$ loading was carefully measured from the weight difference of the $\mathrm{NiF}$ support before and after the incorporation of $\mathrm{CeO}_{2}$.

\subsection{Catalyst activity test}

The DRP with $\mathrm{CO}_{2}$ was carried out in a thermo-catalytic

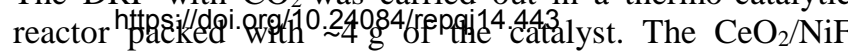

catalyst prepared as above was trimmed into coin-shaped pieces (diameter: $20.8 \mathrm{~mm}$ ) which were stacked one by one along the axis of the reactor tube. The catalytic activity was studied in the temperature range of $520-600^{\circ} \mathrm{C}$ for all the catalysts with different $\mathrm{CeO}_{2}$ loadings. The reactant gases were fed into the reactor at the proportion of 10:30:60 $\left(\mathrm{C}_{3} \mathrm{H}_{8}: \mathrm{CO}_{2}: \mathrm{N}_{2}\right)$. The total flow rate was fixed at $300 \mathrm{ml} \mathrm{min}{ }^{-1}$ throughout this work. During the reforming reaction, the concentrations of relevant components were analyzed by the GC. The overall reaction of the DRP with $\mathrm{CO}_{2}$ can be written as follows:

$\mathrm{C}_{3} \mathrm{H}_{8}+3 \mathrm{CO}_{2}=6 \mathrm{CO}+4 \mathrm{H}_{2}, \Delta \mathrm{H}^{\circ}{ }_{298 \mathrm{~K}}=644.8 \mathrm{kJmol}^{-1}$

It is well known that such a strong endothermic reaction is favored at high temperatures. The conversion $\left(\mathrm{X}_{\mathrm{A}}\right)$ of $\mathrm{C}_{3} \mathrm{H}_{8}$ or $\mathrm{CO}_{2}$ was calculated using the equation below, taking the fractional change in the volumetric flow rate into account [5].

$$
\begin{aligned}
& \mathrm{X}_{\mathrm{A}}(\%)=\frac{\mathrm{C}_{\mathrm{A} 0}-\mathrm{C}_{\mathrm{A}}}{\mathrm{C}_{\mathrm{A} 0}+\varepsilon_{\mathrm{A}} \mathrm{C}_{\mathrm{A}}} \times 100(\%) \\
& \text { Here, }{ }^{\mathrm{C}_{\mathrm{A} 0} \text { and }} \mathrm{C}_{\mathrm{A}} \text { are the inlet and outlet concentrations of }
\end{aligned}
$$

the reactant $\left(\mathrm{C}_{3} \mathrm{H}_{8}\right.$ or $\left.\mathrm{CO}_{2}\right)$, and ${ }^{\varepsilon_{\mathrm{A}}}$ is defined as

$$
\varepsilon_{\mathrm{A}}=\frac{\eta_{\mathrm{X}_{\mathrm{A}}=1}-\eta_{\mathrm{X}_{\mathrm{A}}=0}}{\eta_{\mathrm{X}_{\mathrm{A}}=0}}
$$

where $\eta_{X_{A}=0}$ and $\eta_{X_{A}=1}$ stand for the total number of moles of reactants (no conversion) and the total number of moles of products (complete conversion), respectively. For an inlet feed gas composition of $\mathrm{C}_{3} \mathrm{H}_{8}(10 \%), \mathrm{CO}_{2}(30 \%)$ and $\mathrm{N}_{2}(60 \%), \varepsilon_{\mathrm{A}}$ is calculated to be 0.6 by equation (3).

\section{Results}

Fig. 1 shows the X-ray diffractograms of the 2-4 wt. \% $\mathrm{CeO}_{2} / \mathrm{NiF}$ catalysts along with the bare NiF. In the XRD pattern, the strong diffraction peaks from $\mathrm{NiF}$ can be indexed to the (111), (200), and (220) planes of $\mathrm{Ni}$ (JCPDS 87-0712) [6]. In addition, the XRD patterns of all the three $\mathrm{CeO}_{2}$ loaded catalysts in Fig. 1 showed well resolved cubic $\mathrm{NiO}$ diffraction peaks which can be indexed to the JCPDS 47-1049. Noticeably, the $\mathrm{NiO}$ diffraction peaks intensity has been varied corresponding to the amount of ceria loading. The absence of diffraction peak related to ceria in XRD pattern of 2 wt. $\% \mathrm{CeO}_{2} / \mathrm{NiF}$ catalyst ascribes the complete incorporation of $\mathrm{Ce}^{3+}$ ions into surface $\mathrm{NiO}$ layer. For 3 wt. $\% \mathrm{CeO}_{2}$ loaded sample, it can be seen that the formation of cubic fluorite $\mathrm{CeO}_{2}$ phase. To our surprise the negligible intensity of $\mathrm{NiO}$ diffraction peaks in Fig.1c, associates the predominant phase segregation of ceria over $\mathrm{NiF}$ support. In the meantime, the 4 wt. $\% \mathrm{CeO}_{2} / \mathrm{NiF}$ catalyst exhibited strong diffraction peaks resulting from $\mathrm{NiO}$ as well as $\mathrm{CeO}_{2}$, which may be attributed to the surface oxygen diffusion into metal support to form the more NiO layer. The diffraction peaks of $\mathrm{CeO}_{2}$ promoted catalysts can be directly indexed to (111), (200), (220), (311), and (331) crystal faces, corresponding to the face-centered cubicphase of $\mathrm{CeO}_{2}$ (JCPDS 34-0394, space group Fm3m) [7$8]$. 


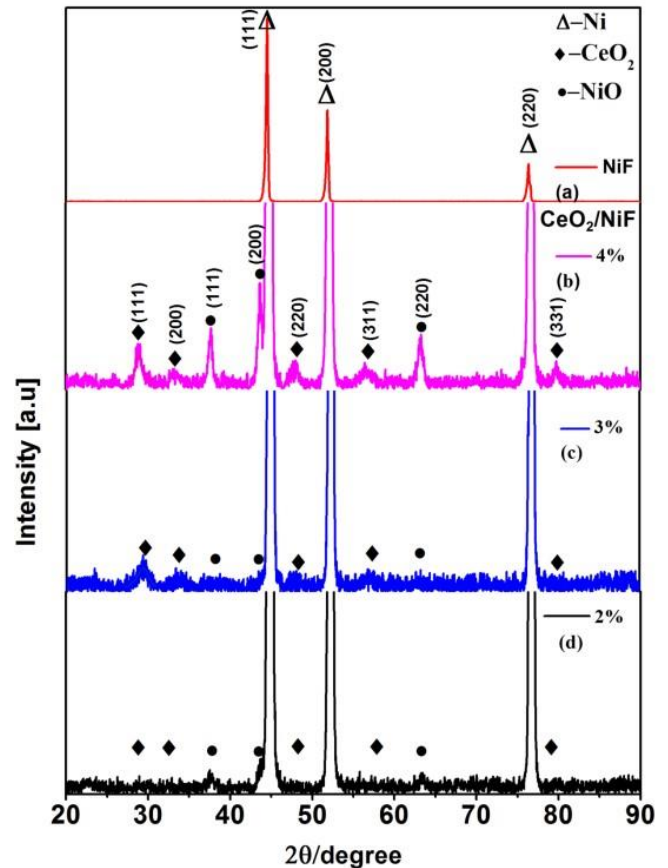

Fig. 1. X-ray diffractograms of (a) bare NiF, (b) 4 wt.\% $\mathrm{CeO}_{2} / \mathrm{NiF}$, (c) 3 wt. $\% \mathrm{CeO}_{2} / \mathrm{NiF}$ and (d) 2 wt. $\% \mathrm{CeO}_{2} / \mathrm{NiF}$.

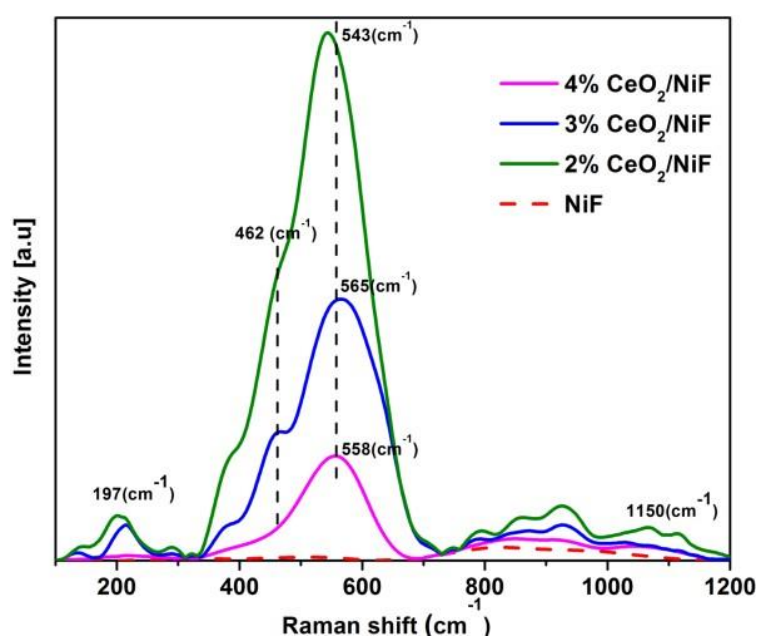

Fig. 2. Raman spectra of the $\mathrm{NiF}$ support and $\mathrm{CeO}_{2} / \mathrm{NiF}$ catalysts with different ceria contents before the DRP.

Fig. 2 presents the Raman spectra of the $2-4 \% \mathrm{CeO}_{2}$ promoted $\mathrm{NiF}$ catalysts and bare NiF. The Raman spectrum of the bare NiF did not reflect any characteristic Raman vibrations, which indicates the metallic nature and relatively high purity of the $\mathrm{NiF}$. On the other hand, the incorporation of $\mathrm{CeO}_{2}$ showed significant variations in the Raman spectra. For all the catalysts, we observe Raman bands from $\mathrm{NiO}$ and $\mathrm{CeO}_{2}$ in the spectra region of above $400 \mathrm{~cm}^{-1}$. All the three spectra showed broad Raman band at $570 \mathrm{~cm}^{-1}$, suggesting that the first-order one phonon (1P) $\mathrm{LO}$ mode of $\mathrm{NiO}$ layer. Whereas the low intensity Raman bands over the spectral region between 700 - $1100 \mathrm{~cm}^{-1}$ correspond to the second-order two phonon (2P) vibrational modes [9-11]. Noticeably, the intensity of the defect-induced $\mathrm{D}$ band $\left(\sim 570 \mathrm{~cm}^{-1}\right)$ varied with the Ce content (2-4 wt. \%) according to the symmetry-breaking imperfections including defects, $\mathrm{Ni}$ and oxygen vacancies or disorder in the crystal lattice [12]. Furthermore, the Ni-O stretching mode has been shifted towards high frequency region from $543 \mathrm{~cm}^{-1}$ to $565 \mathrm{~cm}^{-1}$ for 2 and $3 \% \mathrm{CeO}_{2}$ loaded catalysts. In the case of $4 \% \mathrm{CeO}_{2}$ promoted catalyst, the Ni$\mathrm{O}$ band $\sim 7 \mathrm{~cm}^{-1}$ blue-shifted which indicates the direct

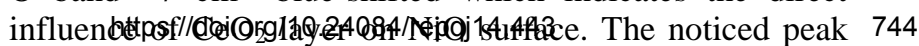
shifts and its broadening depend on various parameters, i.e. oxygen vacancies, phonon confinement, and in homogeneous strain related to the reduced ceria [13-14]. From this observation it can be understandable that presence of defects in the $\mathrm{CeO}_{2}$ promoted NiF catalysts. The ratio between defects-related band and characteristic band gives information on the relative structural disorder (RSD) in the solid solution [15]. As can be seen from Fig. 3 , for 2 and 3 wt. $\% \mathrm{CeO}_{2} / \mathrm{NiF}$ catalysts show a prominent band at around $460 \mathrm{~cm}^{-1}$, corresponding to the $F_{2 g}$ vibration of the cubic fluorite type $\mathrm{CeO}_{2}$ that support the observations made from the XRD studies. To increase the Ce concentration to $4 \%$, the $\mathrm{F}_{2 \mathrm{~g}}$ band of $\mathrm{CeO}_{2}$ suppressed and exhibit in negligible intensity ascribes that homogeneous dispersion of $\mathrm{Ce}$ ions into the $\mathrm{NiO}$ lattices. This is the fact that the crystallinity of the $\mathrm{NiO}$ improves when the $\mathrm{CeO}_{2}$ layer is inserted which is concordance with the XRD results as discussed earlier. From the Raman spectra, it can be concluded that the formation of more $\mathrm{Ce}$ $\mathrm{Ni}-\mathrm{O}$ solid solution for the 4 wt. $\% \mathrm{CeO}_{2} / \mathrm{NiF}$ catalyst which leads to the excellent catalytic activity towards propane reforming reaction [16]. The additional peaks appeared at 221 and $1120 \mathrm{~cm}^{-1}$ may be ascribed to the stretching vibrations of $\mathrm{Ni}-\mathrm{O}$ or related defects on $\mathrm{NiF}$ surface.

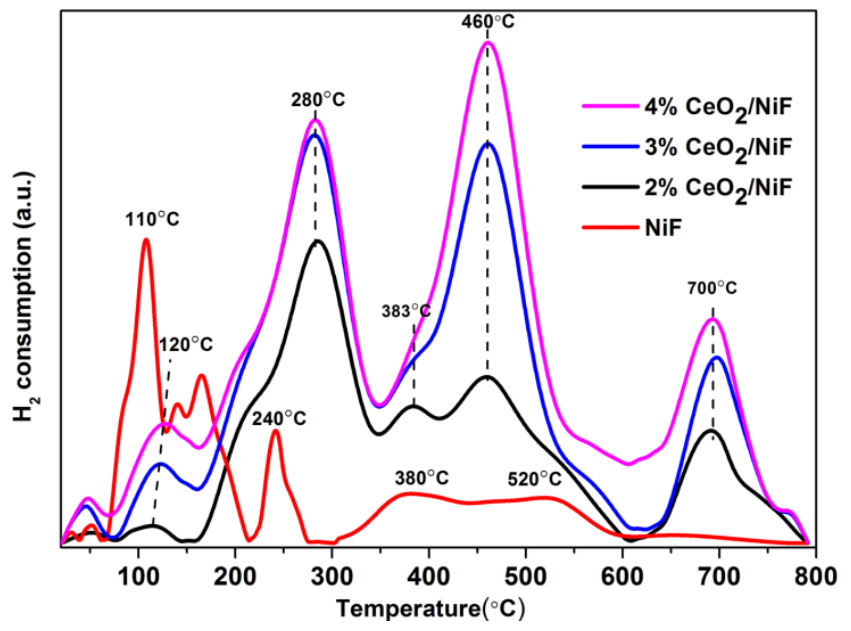

Fig. 3. TPR profiles of the $\mathrm{NiF}$ support and $\mathrm{CeO}_{2} / \mathrm{NiF}$ catalysts with different ceria contents.

The $\mathrm{H}_{2}$-TPR profiles of the prepared catalysts are shown in Fig. 3. It is well demonstrated that pure ceria exhibits two step reduction processes due to reduction of surface oxygen and bulk-phase lattice oxygen; one at $527^{\circ} \mathrm{C}$, which is associated to the surface reduction and the other at $700{ }^{\circ} \mathrm{C}$ due to the bulk reduction. For the bare $\mathrm{NiF}$, two low- temperature reduction peaks appeared at around $240^{\circ} \mathrm{C}$ and $380^{\circ} \mathrm{C}$, and a high-temperature reduction peak at $520^{\circ} \mathrm{C}$. A strong peak observed at around $110^{\circ} \mathrm{C}$ can be attributed to the reduction of impurities [17]. The first peak (between 300 and $450{ }^{\circ} \mathrm{C}$ ) is ascribed to the reduction of the surface $\mathrm{Ni}$ species. The second peak $\left(450 \sim 600{ }^{\circ} \mathrm{C}\right)$ is related to the reduction of bulk $\mathrm{Ni}$ species associated to $\mathrm{NiF}$ support [18-20]. However, Shan et al. explained these overlapped peaks by the different steps in the oxidation state of $\mathrm{Ni}$, from $\mathrm{Ni}^{2+}$ to $\mathrm{Ni}^{0}$ [21]. All the three $\mathrm{CeO}_{2} / \mathrm{NiF}$ catalysts exhibited three peaks in their TPR profiles. The first peak at $280{ }^{\circ} \mathrm{C}$ resulted from the reduction of the oxygen species adsorbed on the vacant sites generated by the incorporation of $\mathrm{Ce}^{4+}$ ions into the $\mathrm{NiO}$ lattice, the second peak at $460{ }^{\circ} \mathrm{C}$ from the reduction of $\mathrm{Ni}$ from $\mathrm{NiO}$ layer, and the third peak at $700{ }^{\circ} \mathrm{C}$ from the reduction of ceria

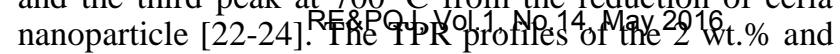


3 wt. $\% \mathrm{CeO}_{2} / \mathrm{NiF}$ were similar to that of the 4 wt. $\%$ equivalent. The reduction peak at around $280^{\circ} \mathrm{C}$ is due to lower enthalpy of reduction, the surface bounded $\mathrm{CeO}_{2}$ are first reduced at lower temperatures followed by the reduction at around $460^{\circ} \mathrm{C}$ due to $\mathrm{NiO}$ species which has been strongly coupled with $\mathrm{CeO}_{2}$ [22]. Besides, the intensity of the second $\mathrm{H}_{2}$ consumption peak for the 4 wt.\% $\mathrm{CeO}_{2} / \mathrm{NiF}$ was stronger than the $2-3 \mathrm{wt} . \%$ equivalent, suggesting that there were more number $\mathrm{NiO}$ species are actively contributed to reduction reaction in combination with $\mathrm{CeO}_{2}$. When compared to $2-3 \% \mathrm{wt} \%$, the $\mathrm{H}_{2}$ consumption peak area for all the three reduction process were increased significantly with the $\mathrm{CeO}_{2}$ content, indicating that the effective contribution of ceria surface oxygen.

Fig. 4 shows the propane and $\mathrm{CO}_{2}$ conversion efficiencies as a function of temperature. The propane and $\mathrm{CO}_{2}$ conversion increased with increasing the temperature for all the catalysts. As the temperature increases, the oxygen mobility increases and more lattice oxygen atoms are also involved in the reaction [25], this improves the propane and $\mathrm{CO}_{2}$ conversions. As indicated in Fig. 4, the $\mathrm{CeO} 2$ content had a significant influence on the catalytic performance. The bare $\mathrm{NiF}$ exhibited a relatively poor catalytic activity even at a temperature as high as $600^{\circ} \mathrm{C}$. The conversions are gradually increased as the $\mathrm{CeO}_{2}$ content up to $3 \mathrm{wt}$. \%. Further increasing to $4 \mathrm{wt}$. \% resulted in a drastic increase in the catalytic activity, even at low temperatures. The excellent conversions of propane and $\mathrm{CO}_{2}$ were achieved with this catalyst at a temperature as low as $520^{\circ} \mathrm{C}$ which is about $86 \%$ and $65 \%$, respectively, reaching $95 \%$ and $93 \%$ when the temperature reached to $600^{\circ} \mathrm{C}$. Whereas, the 3 wt. $\% \mathrm{CeO}_{2} / \mathrm{NiF}$ catalyst exhibited only $63 \%$ and $57 \%$ conversions for propane and $\mathrm{CO}_{2}$ even at $600{ }^{\circ} \mathrm{C}$, and it is $50 \%$ and $44 \%$ for 2 wt. $\% \mathrm{CeO}_{2} / \mathrm{NiF}$ catalyst at the same temperature. Meanwhile, the $\mathrm{CO}_{2}$ conversions obtained for the bare $\mathrm{NiF}, 2$ wt. $\% \mathrm{CeO}_{2} / \mathrm{NiF}$ and 3 wt. $\% \mathrm{CeO}_{2} / \mathrm{NiF}$ over the temperature range of $520-600^{\circ} \mathrm{C}$ were higher than the corresponding propane conversions, which may be due to reverse water shift reaction (RWGS), but also to carbon gasification by $\mathrm{CO}_{2}[26]$.

$$
\begin{aligned}
& \mathrm{CO}_{2}+\mathrm{H}_{2}=\mathrm{H}_{2} \mathrm{O}+\mathrm{CO}, \Delta \mathrm{H}^{\mathrm{o}}{ }_{298 \mathrm{~K}}=41 \mathrm{kJmol}^{-1} \\
& \mathrm{C}+\mathrm{H}_{2} \mathrm{O}=\mathrm{H}_{2}+\mathrm{CO}_{2}, \Delta \mathrm{H}^{\mathrm{o}}{ }_{298 \mathrm{~K}}=131 \mathrm{kJmol}^{-1}
\end{aligned}
$$

The $\mathrm{CO}_{2}$ conversion occurs via two pathways such as the conversion of $\mathrm{CO}_{2}$ adsorbed on $\mathrm{CeO}_{2}$ and the dissociation of $\mathrm{CO}_{2}$ adsorbed on oxygen vacancies. The dissociation of $\mathrm{CO}_{2}$ adsorbed on oxygen vacancies can provide supplementary oxygen and be helpful to the oxygen mobility [27]. Among the different $2-4 \% \mathrm{CeO}_{2} / \mathrm{NiF}$ catalysts studied, the $4 \% \mathrm{CeO}_{2} / \mathrm{NiF}$ compound has been chosen not only because of its good performance in DPR activity but also because its homogeneity over $\mathrm{NiF} / \mathrm{NiO}$ surface in the form of solid solution. XRD analysis of 2$4 \% \mathrm{CeO}_{2} / \mathrm{NiF}$ catalyst clearly shows $\mathrm{NiO}$ and $\mathrm{CeO}_{2}$ phases that indicates the strong interaction of $\mathrm{Ce}^{4+}$ into $\mathrm{NiF}$ increases $\mathrm{NiO}$ phase segregation for $4 \%$ of $\mathrm{CeO}_{2} / \mathrm{NiF}$. These $\mathrm{NiO}$ species present the characteristic of being able to be reduced and reoxidized easily and generated vacancy can be refilled by $\mathrm{CeO}_{2}$ lattice oxygen. Hence, it can be expected that the $\mathrm{NiO}$ species on the surface of $4 \% \mathrm{CeO}_{2} / \mathrm{NiF}$ sample provides adequate active oxygen species for DRP. The formed oxygen vacancies can be refilled by migration of the oxygen from the $\mathrm{CeO}_{2}$ lattice

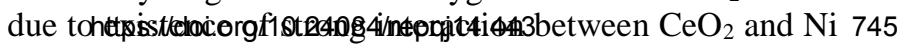
species (evidence from $\mathrm{H}_{2}$-TPR studies, Raman and XRD).
Therefore, it can be suggested that the reducible nature of the Ni species plays a beneficial role in the DRP activity of the $4 \% \mathrm{CeO}_{2} / \mathrm{NiF}$.

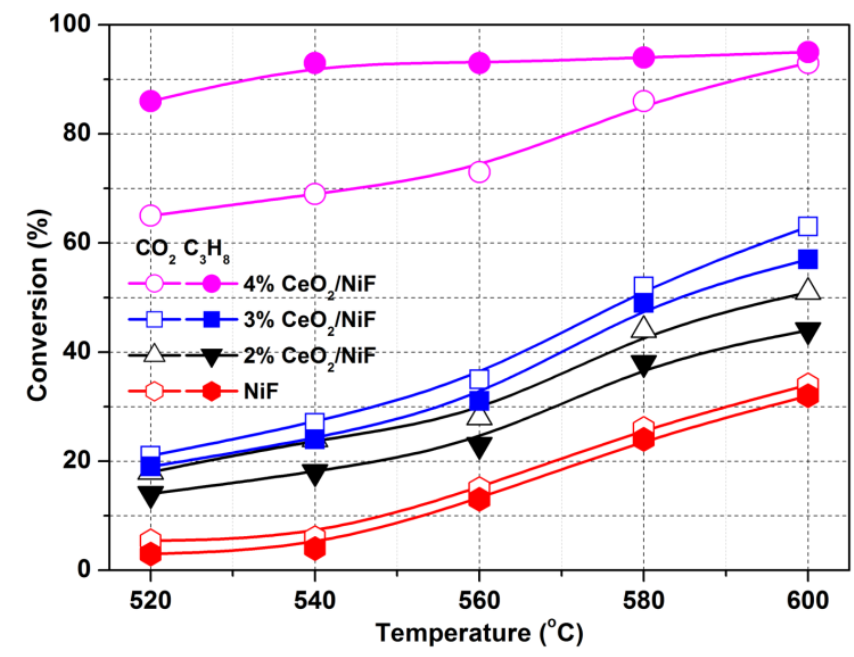

Fig. 4. $\mathrm{C}_{3} \mathrm{H}_{8}$ and $\mathrm{CO}_{2}$ conversion efficiencies obtained with the $\mathrm{NiF}$ support and $\mathrm{CeO}_{2} / \mathrm{NiF}$ catalysts with $\mathrm{d}$ ifferent ceria contents.
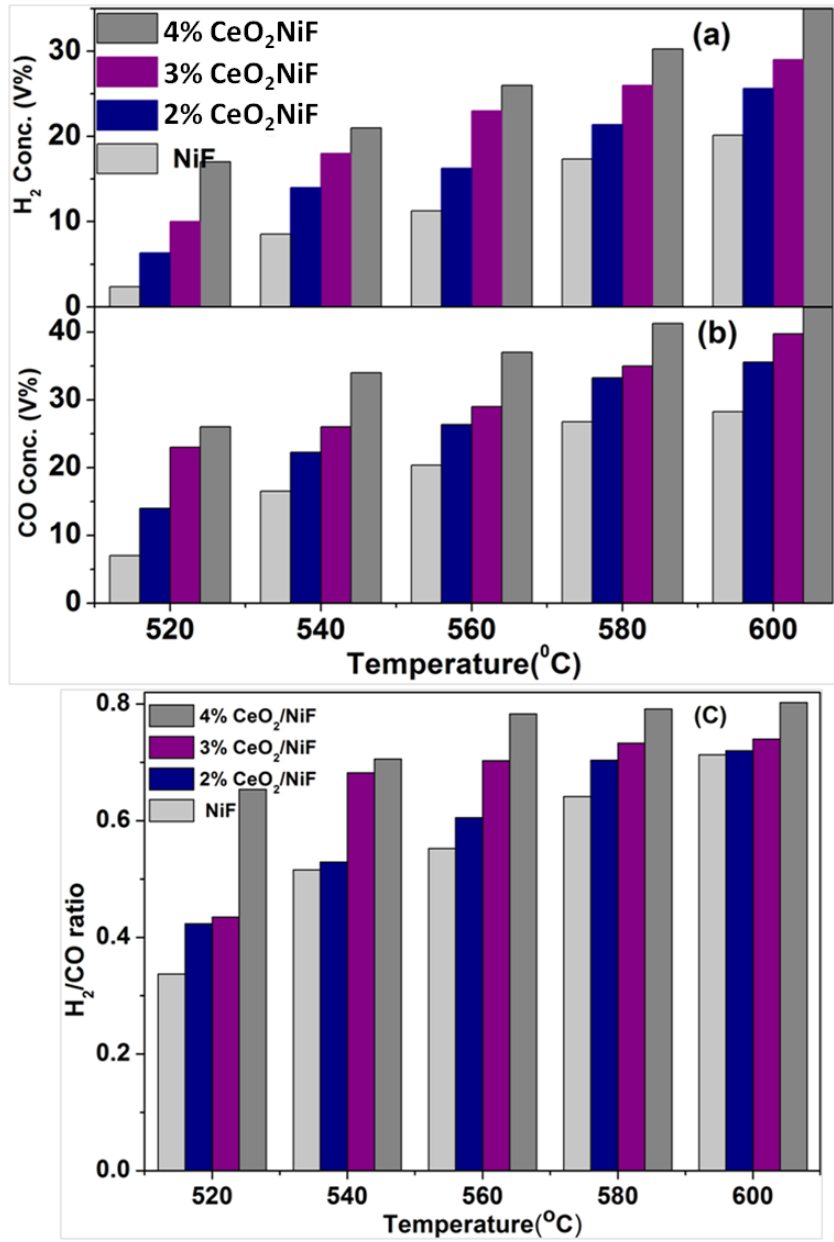

Fig. 5. Concentrations of (a) $\mathrm{H}_{2}$ and (b) $\mathrm{CO}$ produced, and (c) $\mathrm{H}_{2} / \mathrm{CO}$ ratios achieved by the $\mathrm{NiF}$ support and $\mathrm{CeO}_{2} / \mathrm{NiF}$ catalysts with different ceria contents.

The concentrations of $\mathrm{H}_{2}$ and $\mathrm{CO}$ during the DRP are illustrated in Fig. 5a-b. The 4 wt. $\% \mathrm{CeO}_{2} / \mathrm{NiF}$ showed higher activity than the other three catalysts in terms of $\mathrm{H}_{2}$ and $\mathrm{CO}$ production. The concentration of $\mathrm{CO}$ was higher than that of $\mathrm{H}_{2}$ at all temperatures, and the concentrations of both gases increased with increasing the temperature. Due to the high endothermicity of the dry reforming, an increase in the temperature is beneficial to the conversions of $\mathrm{C}_{3} \mathrm{H}_{8}$ and $\mathrm{CO}_{2}$ and therefore the production of $\mathrm{H}_{2}$ and 
CO [28]. With 4 wt.\% catalyst, the propane conversion is higher than that of $\mathrm{CO}_{2}$ (Fig. 5), but with the other catalysts, $\mathrm{CO}_{2}$ conversion is higher than propane conversion. However, the catalyst having the higher loading of $\mathrm{CeO}_{2}$ exhibits higher activity. One explanation of this behavior could the high mobility of activated oxygen caused by high concentration of ceria in the lattice and surface of supports, which favors the reaction of this activated oxygen with propane from gas phase. The $\mathrm{H}_{2} / \mathrm{CO}$ ratio obtained at various reaction temperatures is illustrated in Fig. 5c. For all the catalysts, the $\mathrm{H}_{2} / \mathrm{CO}$ ratios were less than unity, and the ratio increased with increasing the temperature. Increasing reaction temperature led to an increased value for the ratio of $\mathrm{H}_{2} / \mathrm{CO}$ due to the suppressed reversed water-gas shift reaction at high temperature. At all temperatures, the $\mathrm{H}_{2} / \mathrm{CO}$ ratio produced by the 4 wt. $\% \mathrm{CeO}_{2} / \mathrm{NiF}$ catalyst was larger than those by the other catalysts.

\subsection{Long-term stability tests of $\mathrm{CeO}_{2} / \mathrm{NiF}$ catalysts.}

The long-term stability of the $\mathrm{CeO}_{2} / \mathrm{NiF}$ catalysts for the DRP was examined at $540^{\circ} \mathrm{C}$ for $24 \mathrm{~h}$, and the results are shown in Fig.6. As mentioned earlier in relation to Fig. 4, the incorporation of $\mathrm{CeO}_{2}$ into the $\mathrm{NiF}$ enhanced the catalytic activity towards the DRP. The initial propane and $\mathrm{CO}_{2}$ conversions obtained with the 4 wt. $\% \quad \mathrm{CeO}_{2} / \mathrm{NiF}$ catalyst were 93 and $68 \%$. As shown in Fig. 6, the 4 wt.\% $\mathrm{CeO}_{2} / \mathrm{NiF}$ catalyst underwent slight deactivation after $24 \mathrm{~h}$, but the degree of deactivation was not significant. The propane conversion decreased to $89 \%$, while the $\mathrm{CO}_{2}$ conversion to $61 \%$. The activity of the $3 \mathrm{wt}$. $\%, 2 \mathrm{w} \%$ $\mathrm{CeO}_{2} / \mathrm{NiF}$ supports was also outstandingly improved after the $\mathrm{CeO}_{2}$ addition, which indicates the importance of $\mathrm{CeO}_{2}$ in the dry reforming reaction for long term stability. Generally, stability of the catalysts can be reflected by three experimental phenomena: apparent thermal stability of supports and the catalysts, high metal dispersion and carbon deposition of the catalysts. Many factors including basicity of supports, concentrations of surface oxygen vacancies, oxygen storage capacity, interaction between support and metal and microstructures of the catalysts can significantly affect the observation in the morphological changes and catalytic activity of the catalysts.

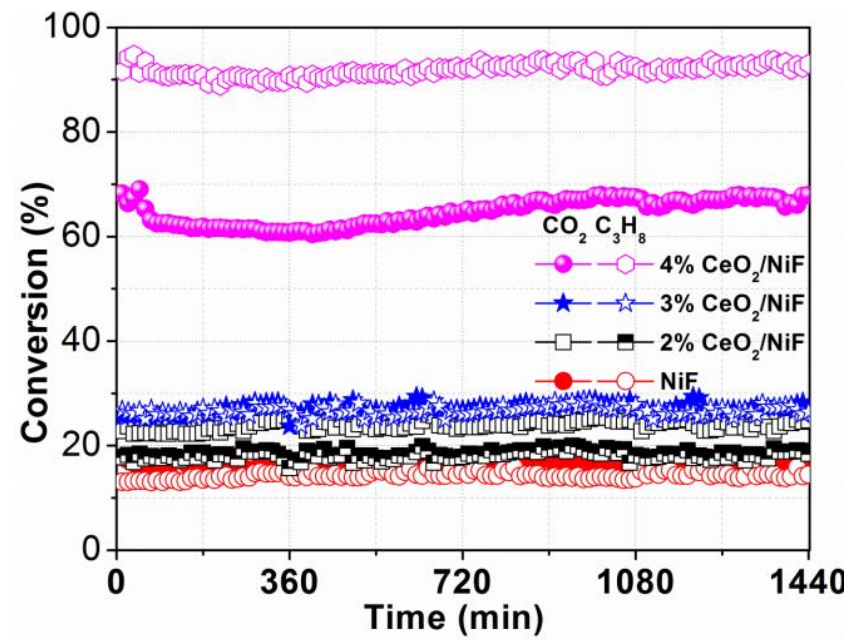

Fig. 6. Stability of the catalysts in term of $\mathrm{CO}_{2} \& \mathrm{C}_{3} \mathrm{H}_{8}$ conversions over the time period of $24 \mathrm{~h}$ at $540{ }^{\circ} \mathrm{C}$.

It is well known that the Raman spectroscopy is the powerful tool to observe the internal chemical structure and presence of carbonaceous element. Also Raman spectra can give us the more information about the nature of carbonaceous deposits on the used catalysts. Fig. T. displays the Raman spectra of the used catalysts, where two major peaks at $1341 \mathrm{~cm}^{-1}$ (D band) and $1576 \mathrm{~cm}^{-1}$ ( $\mathrm{G}$ band) were clearly observed in all the used $\mathrm{CeO}_{2} / \mathrm{NiF}$ catalysts [28]. The high intensity D-modes at 1341 $\mathrm{cm}^{-1}$ substantiates the presence of large amount of disordered graphitic carbon has been formed as the byproducts which reduce the catalytic activity. The ratio of intensities of the $D$ and $\mathrm{G}$ maximums ( $\mathrm{I}_{\mathrm{D}}$ and $\mathrm{I}_{\mathrm{G}}$ ) gives an indication of the crystallinity of the studied material.

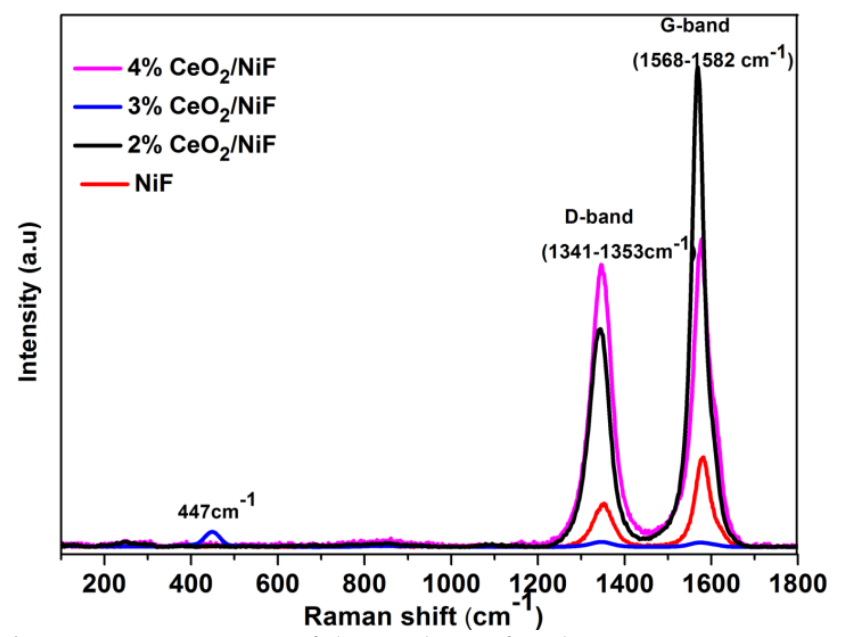

Fig. 7. Raman spectra of the catalysts after the DRP.

The lower value of $\mathrm{I}_{\mathrm{D}} / \mathrm{I}_{\mathrm{G}}$ points out on higher crystallinity, while the higher ratio suggests on the higher disorder within the crystalline structure. Highly oriented pyrolytic graphite (HOPG) has an $\mathrm{I}_{\mathrm{D}} / \mathrm{I}_{\mathrm{G}}$ ratio approaching 0 , while amorphous carbon has a value near 3.3. The $3 \% \mathrm{CeO}_{2} / \mathrm{NiF}$ of used catalyst after reaction showed an average $\mathrm{I}_{\mathrm{D}} / \mathrm{I}_{\mathrm{G}}$ value of $\sim 1.3$, that is, higher than the ratio $(\sim 0.91)$ of the $4 \% \mathrm{CeO}_{2} / \mathrm{NiF}$ catalyst indicates the more amorphous carbon was formed in $3 \% \mathrm{CeO}_{2}$ catalyst. Typical D-mode peaks for $3 \% \mathrm{CeO}_{2}$ catalyst exhibit the as equal to G-band $( \pm 10)$ as shown in Fig.7. However, in $4 \%$ $\mathrm{CeO}_{2} / \mathrm{NiF}, 2 \% \mathrm{CeO}_{2} / \mathrm{NiF}$, and bare $\mathrm{NiF}, \mathrm{D}$ band is less intense than the $G$ band. It seemed that carbon species were not uniformly distributed over the catalyst surface [29]. According to earlier reports band is much more intense despite a higher disorder degree. These may be explained by the different carbon species are presented with some better ordered than others [29].

\section{Conclusions}

In summary, $2-4$ wt. $\% \mathrm{CeO}_{2} / \mathrm{NiF}$ catalysts were prepared by wet impregnation method and characterized by various techniques. The XRD results suggested the formation of nano-oxides with sizes of $\sim 5-16 \mathrm{~nm}$. The Raman band at $620 \mathrm{~cm}^{-1}$ indicated that the lattice oxygen was significantly higher in $4 \% \mathrm{CeO}_{2} / \mathrm{NF}$ sample. XRD analysis revealed the formation of a rich ceria phase at higher loading $>3 \% \mathrm{CeO}_{2}$ on NF. TPR measurements revealed strong interactions between $\mathrm{CeO}_{2}$ and $\mathrm{NiF}$ support and that facilitate reduction at lower temperatures. In addition, various sized $\mathrm{CeO}_{2}$ nano particles with spherical morphology were dispersed over the surface of the supports. The TPR data also supported the incorporation of ceria into the $\mathrm{NiO}$ surface layer formed over NiF support, which was substantially higher in $4 \%$ $\mathrm{CeO}_{2} / \mathrm{NF}$ catalyst. Due to these favorable properties, the $4 \mathrm{wt}$. \% $\mathrm{CeO}_{2} / \mathrm{NiF}$ could be considered as an excellent catalysts for propane reforming reaction. DRP with $\mathrm{CO}_{2}$ over the prepared catalysts follows the order 4 wt. $\% \mathrm{CeO}_{2} / \mathrm{NiF}>3$ wt. $\% \mathrm{CeO}_{2} / \mathrm{NiF}>2$ wt. $\% \mathrm{CeO}_{2} / \mathrm{NiF}>$ bare NiF. Among the different catalysts, the 4 wt. $\% \mathrm{CeO}_{2} / \mathrm{NiF}$ catalyst showed excellent activity at $540^{\circ} \mathrm{C}$ and $92 \%$ of propane and $70 \%$ of $\mathrm{CO}_{2}$ conversion. The better DRP activity of 4 wt. $\% \mathrm{CeO}_{2} / \mathrm{NiF}$ is due to the fluorite lattice of ceria and the accompanied generation of oxygen vacancies in the catalyst. As a result, the higher catalytic activity, better catalytic stability and higher coke resistance of $2-4$ wt. $\% \quad \mathrm{CeO}_{2} / \mathrm{NiF}$

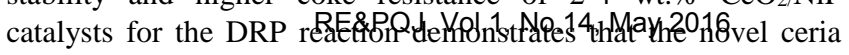


promoted porous $\mathrm{NiF}$ as a promising support for high temperature catalytic reaction.

\section{Acknowledgements}

This research was supported by Basic Science Research Program through the National Research Foundation of Korea (NRF) funded by the Ministry of Science, ICT and Future Planning (Grant No. 2013R1A2A2A01067961).

\section{References}

[1] A. Jha, D.-W. Jeong, W.-J. Jang, C. V. Rode and H.-S. Roh, RSC Advances, 2015, 5, 1430-1437.

[2] L. B. Råberg, M. B. Jensen, U. Olsbye, C. Daniel, S. Haag, C. Mirodatos and A. O. Sjåstad, Journal of Catalysis, 2007, 249, 250-260.

[3] X. Xiong, D. Ding, D. Chen, G. Waller, Y. Bu, Z. Wang and M. Liu, Nano Energy, 2015, 11, 154-161.

[4] J. Xiong, X. Dong, Y. Dong, X. Hao and S. Hampshire, International Journal of Hydrogen Energy, 2012, 37, 1230712316.

[5] J. Karuppiah and Y. S. Mok, Int. J. Hydrogen Energy, 2014, 39, 16329-16338.

[6] H. Yan, D. Zhang, J. Xu, Y. Lu, Y. Liu, K. Qiu, Y. Zhang and Y. Luo, Nanoscale Res Lett, 2014, 9, 1-7.

[7] J. Zhang, H. Yang, S. Wang, W. Liu, X. Liu, J. Guo and Y. Yang, Cryst.Eng. Comm, 2014, 16, 8777-8785.

[8] C. Sun, J. Sun, G. Xiao, H. Zhang, X. Qiu, H. Li and L. Chen, J. Phys. Chem. B, 2006, 110, 13445-13452.

[9] L. De Los Santos Valladares, A. Ionescu, S. Holmes, C. H. W. Barnes, A. Bustamante Domínguez, O. Avalos Quispe, J. C.

González, S. Milana, M. Barbone, A. C. Ferrari, H. Ramos and Y. Majima, J. Vac. Sci. Technol B, 2014, 32, 051808.

[10] R. E. Dietz, W. F. Brinkman, A. E. Meixner and H. J.

Guggenheim, Phys. Rev. Lett, 1971, 27, 814-817.

[11] R. E. Dietz, G. I. Parisot and A. E. Meixner, Phys. Rev. B: Condens. Matter, 1971, 4, 2302-2310.

[12] P. A. Fleury and R. Loudon, Phys. Rev, 1968, 166, 514-530.

[13] P. Sudarsanam, B. Mallesham, D. N. Durgasri and B. M.

Reddy, RSC Advances, 2014, 4, 11322-11330.

[14] B. M. Reddy, P. Bharali, P. Saikia, A. Khan, S. Loridant, M Muhler and W. Grünert, Phys. Chem. C, 2007, 111, 1878-1881.

[15] S. Rossignol, F. Gerard, D. Mesnard, C. Kappenstein and D. Duprez, J. Mater. Chem, 2003, 13, 3017-3020.

[16] S. Mahammadunnisa, P. Manoj Kumar Reddy, N. Lingaiah and C. Subrahmanyam, Catal. Sci. Technol, 2013, 3, 730-736.

[17] A. Zawadzki, J. D. A. Bellido, A. F. Lucrédio and E. M. Assaf, Fuel Process. Technol, 2014, 128, 432-440.

[18] J. Marrero-Jerez, A. Murugan, I. S. Metcalfe and P. Núñez, Ceram. Int, 2014, 40, 15175-15182.

[19] Y. Wei, H. Wang, K. Li, X. Zhu and Y. Du, J. Rare Earths, 2010, 28, Supplement 1, 357-361.

[20] L. Liu and L. Hong, Appl. Catal., A, 2013, 459, 89-96.

[21] W. Shan, M. Luo, P. Ying, W. Shen and C. Li, Appl. Catal., A, 2003, 246, 1-9.

[22] J. Hu, C. Yu, Y. Bi, L. Wei, J. Chen and X. Chen, Chinese J. Catal, 2014, 35, 8-20.

[23] B. Zapata, M. A. Valenzuela, J. Palacios and E. Torres-Garcia, Int. J. Hydrogen Energy, 2010, 35, 12091-12097.

[24] L. Pino, A. Vita, F. Cipitì, M. Laganà and V. Recupero, Appl. Catal., B, 2011, 104, 64-73.

[25] V. Balcaen, R. Roelant, H. Poelman, D. Poelman and G. B.

Marin, Catal. Today, 2010, 157, 49-54.

[26] A. Serrano-Lotina and L. Daza, Int. J. Hydrogen Energy, 2014, 39, 4089-4094.

[27] A. Pantazidis, S. A. Bucholz, H. W. Zanthoff, Y. Schuurman and C. Mirodatos, Catal. Today, 1998, 40, 207-214.

[28] S. Zhang, S. Muratsugu, N. Ishiguro and M. Tada, ACS

Catalysis, 2013, 3, 1855-1864.

[29] D. Liu, X. Y. Quek, W. N. E. Cheo, R. Lau, A. Borgna and Y. 